\title{
Coil Migration Following Transcatheter Arterial Embolization
}

\author{
Yi-Cheng Shen ${ }^{1}$, Chun-Han Liao ${ }^{2}$, Te-Chun Shen ${ }^{1,3}$ and Chih-Yen Tu ${ }^{1}$ \\ Key words: coil migration, transcatheter arterial embolization (TAE), gastrointestinal bleeding
}

(Intern Med 53: 519-520, 2014)

(DOI: 10.2169/internalmedicine.53.1784)
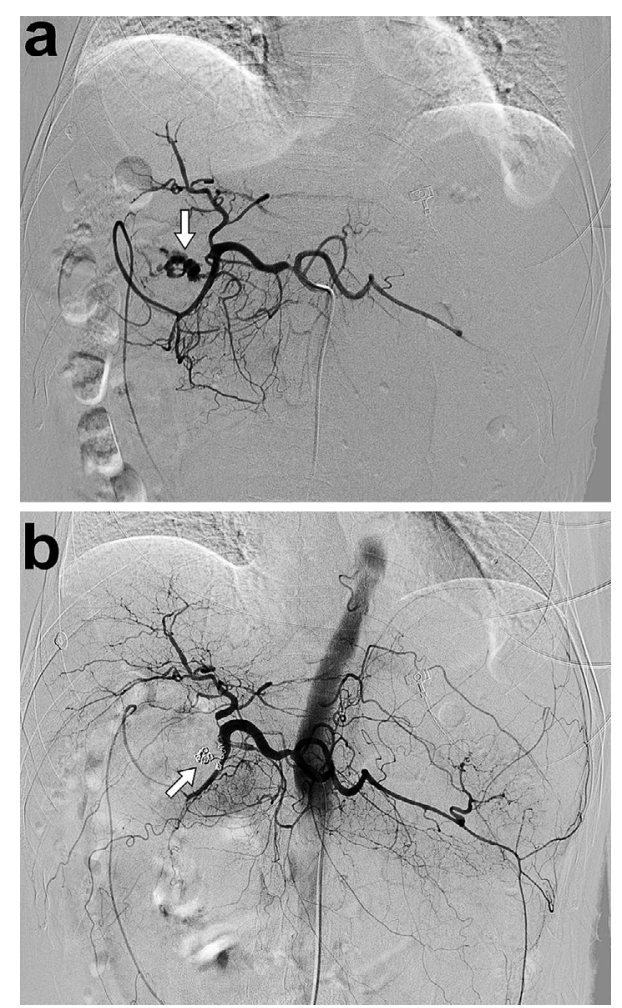

Picture 1.

A 69-year-old man presented with hypovolemic shock caused by massive gastrointestinal bleeding. Angiography revealed active bleeding in a branch of the gastroduodenal artery (Picture 1a). The patient underwent emergent transcatheter arterial embolization (TAE), and angiography confirmed complete occlusion due to bleeding (Picture 1b). The patient's condition rapidly stabilized; however, esophagogastroduodenoscopy performed seven days after TAE showed the presence of duodenal ulcers and a metal material impacted in the duodenal surface (Picture 2). Coil migration

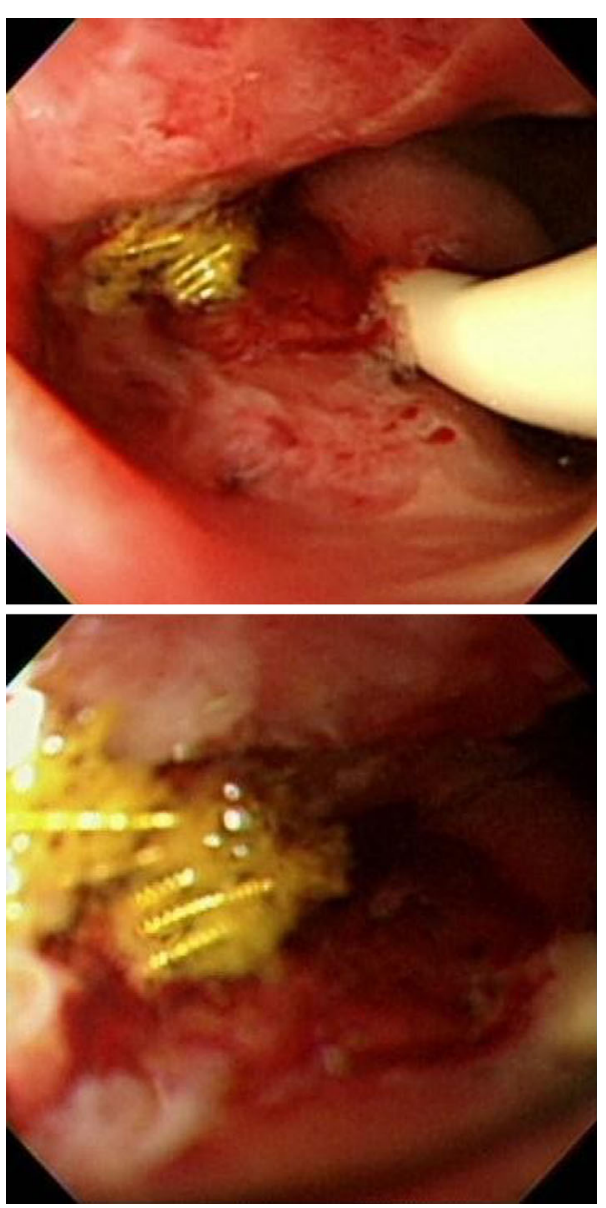

Picture 2.

was highly suspected. We prescribed conservative management, and the patient was discharged after an uneventful hospital stay. No more bleeding episodes or additional sequelae were observed over the following months.

The standard treatment for upper gastrointestinal bleeding

${ }^{1}$ Department of Internal Medicine, China Medical University Hospital and China Medical University, Taiwan, ${ }^{2}$ Department of Radiology, China Medical University Hospital, Taiwan and ${ }^{3}$ Department of Internal Medicine, Chu Shang Show Chwan Hospital, Taiwan Received for publication September 18, 2013; Accepted for publication September 20, 2013 Correspondence to Dr. Te-Chun Shen, chestshen@gmail.com 
is endoscopic hemostasis. TAE is an alternative option for controlling massive bleeding in the stomach or duodenum. The frequency of coil migration has been reported to be approximately $3 \%$ (1). Coil migration and impaction into the intestines has been documented, and conservative treatment is favored in such cases (2).

The authors state that they have no Conflict of Interest (COI).

\section{References}

1. Yap FY, Omene BO, Patel MN, et al. Transcatheter embolotherapy for gastrointestinal bleeding: a single center review of safety, efficacy, and clinical outcomes. Dig Dis Sci 58: 1976-1984, 2013.

2. Chosa K, Naito A, Awai K. Extravascular submucosal coil migration after transcatheter arterial embolization for a massively bleeding duodenal ulcer. Cardiovasc Intervent Radiol 34: 1098-1101, 2011.

\footnotetext{
(C) 2014 The Japanese Society of Internal Medicine http://www.naika.or.jp/imonline/index.html
} 